\title{
OUTCOME OF VITRECTOMY SURGERY IN DROPPED NUCLEUS AT JAKARTA EYE CENTER
}

\author{
Referano Agustiawan, Soedarman Sjamsoe, Waldensius Girsang, Elvioza
}

JEC Eye Hospital

\begin{abstract}
Introduction: To report management and outcome of dropped nucleus in Jakarta Eye Center

Methods: Retrospective review of the records of 19 consecutive patients who underwent pars plana vitrectomy for retain lens fragments at Jakarta Eye Center from January 2010 to September 2012.

Result: The mean age of the patient was 57 years (range 48-79). There were 10 males (53\%) and 9 females (47\%). 10 patients (53\%) had vitrectomy within 1 day of phacoemulsification, 6(32\%) within 1 week and 3(15\%) after more than 1 week. Eight patients (42\%) achieved a final visual acuity of 0.5 or better, only 3 patients (15\%) had final visual acuity 1-meter finger counting or worse. 74\% patient achieved final acuity better than pre-op (14 patients). Early vitrectomy group has 3 patients (30\%) with complication, intermediate vitrectomy group has 33\% complication and late vitrectomy has $33 \%$ complication. Posterior chamber IOL were implanted in 12 patients (63\%), 2 patients had scleral fixation IOL, anterior chamber IOL in 2 patients, and only 3 patients (16\%) were left aphakic.
\end{abstract}

Conclusion: Surgical management in cases of nucleus drop in JEC showed good result with very limited complications. In most cases, vitrectomy was performed immediately after cataract surgery. Early vitrectomy has no significant differences in complications and visual outcome than 1 week vitrectomy and late vitrectomy after cataract surgery.

Keywords: cataract surgery, pars plana vitrectomy, dropped nucleus

Cite This Article: AGUSTIAWAN, referano et al. OUTCOME OF VITRECTOMY SURGERY IN DROPPED NUCLEUS AT JEC Eye Hospitals. International Journal of Retina, [S.I.], v. 1, n. 2, aug. 2018. ISSN 2614-8536. Available at: $<$ https://www.ijretina.com/index.php/ijretina/article/view/28>.

${ }^{*}$ Correspondence to: Referano Agustiawan, JEC Eye Hospital, referanoagustiawan@gmail.com

\section{INTRODUCTION}

Phacoemulsification is becoming increasingly popular in Indonesia. Jakarta Eye Center as a pioneer of this technique in Indonesia has been performing more than 100,000 phaco surgeries since $1984 . \quad$ While phacoemulsification has several major advantages, nucleus and nuclear fragment dislocation is a potentially serious complication of this technique. This complication may occur during hydrodissection, phacoemulsification of the nucleus in the presence of posterior capsular tear, posterior extension of a tear in the coninous curvelinier capsulorrhexis or a zonular dialysis. The more recent literature reports incidence of this complication $0.3 \%$ 2.7\%. ${ }^{1}$ Retained nuclear fragment can result in severe intra ocular inflammation, vitreous hemorrhage, glaucoma, retinal detachment and may lead to loss of useful vision.

The modern management of a nucleus drop requires pars plana vitrectomy by an experienced vitreoretinal surgeon. While successful removal of nuclear fragments can result in good visual recovery, the requisite instrumentation and trained personnel must be available. ${ }^{2}$ However, only $44-69 \%$ of patients who undergo this procedure achieve a final visual acuity of $20 / 40$ or better. ${ }^{3-10}$ The purpose of this study was to evaluate the clinical features and visual outcomes of pars plana vitrectomy in patients with nucleus drop in Jakarta Eye Center. 


\section{PATIENTS and METHODS}

A retrospective review of nucleus drop patient records from January 1, 2010 to September, 2012 at Jakarta Eye Center was performed. The nuclear fragment drop reported here occurred in a consecutive series of 13,340 phacoemulsification performed during period of 2 years. The relevant information was retrieved from patient records. All phacoemulsification surgeries were performed by Jakarta Eye Center doctors.

When facing a nucleus drop case, the protocol in our hospital required the operating surgeon to performed a partial anterior vitrectomy. Unless the clinical impression was that of a hard nucleus, the surgeon would implant IOL (Intra Ocular Lens). In case of doubt a vitreoretinal was consulted and if available depending on media clarity and state of anesthesia, the nuclear fragment was removed at the same sitting. Otherwise patient were managed with an elective 3-port pars plana vitrectomy later. Wire-loop Vectis or similar devices were not used to retrieve sunken nucleus or nuclear fragment.

A three-port pars plana vitrectomy was performed before the nuclear material was removed. Cortical material covering the nucleus and small soft lens fragment removed with vitrector. When the nuclear material was difficult to fragment, it was crushed between the light pipe and vitrector and then removed. If the entire nucleus was in the vitreous, the nucleus was dragged up into the anterior chamber with or without PFCL (Perfluorocarbon Liquid) and removed through an extension of the original scleral tunnel incision or corneal incision. If an IOL had not been implanted during the primary surgery, it was implanted at this time.

The following information was noted for each patient: age, sex, risk factor for lens dislocation, visual acuity before vitrectomy, size of the dislocated lens fragment, interval between cataract surgery and vitrectomy, type of IOL implant, vitrectomy methods, perioperative complication and final visual acuity.

\section{RESULTS}

Total Phacoemulsification surgery in Jakarta Eye Center from 2010 to September 2012 were recorded 13,340. Complication number were occurred in 172 cases (1.3\%). Nineteen nucleus dropped $(0.14 \%)$ were recorded in this period. All of 19 nucleus drop cases were included in this study. The mean age of the patient was 57 years (range 48-79). There were 10 males (53\%) and 9 females (47\%).

\section{Preexisting Eye Disease}

Diabetic Retinopathy (42.1\%), myopic degeneration (10.5\%) and previous retinal detachment (15.8\%) were the most frequent preexisting eye disease (table 1)

Table 1. Preexisting eye disease

\begin{tabular}{lll}
\hline Condition & Number & $\%$ \\
\hline Diabetes Retinopathy & 8 & 42.1 \\
Myopic Degeneration & 2 & 10.5 \\
Post Retinal Detachment & 3 & 15.8 \\
Glaucoma & 1 & 5.3 \\
\hline
\end{tabular}

\section{Risk Factors for dropped Nucleus}

The risk factors for the dislocation of lens fragments during phacoemulsification surgery are presented in table 2 . The most common risk factors included Brown Cataract (47.7\%) and vitrectomized eye (21.1\%)

Table 2. Risk Factor for dropped nucleus

\begin{tabular}{lll}
\hline Risk Factor & Number & $\%$ \\
\hline Brown Cataract & 9 & 47.4 \\
Myopic eye & 2 & 10.5 \\
Vitrectomized eye & 4 & 21.1 \\
Shallow anterior chamber & 1 & 5.3 \\
\hline
\end{tabular}


Table 3. Distribution of age, sex, preexisting eye disease, nucleus size, BCVA, and Lens status in each group

Early Vit Group Intermediate Vit Group Late Vit Group

(10)

(6)

(3)

\begin{tabular}{|c|c|c|c|c|}
\hline $\begin{array}{l}\text { Mean } \\
\text { Age(years) }\end{array}$ & 67 & & 56 & 58 \\
\hline Range & $46-79$ & & $62-73$ & $48-64$ \\
\hline Male/Female & $6 / 4$ & & $3 / 3$ & $1 / 2$ \\
\hline \multicolumn{5}{|c|}{ Vitrectomy type } \\
\hline TSV & 10 & & 5 & 2 \\
\hline Vit & & & 1 & 1 \\
\hline \multicolumn{5}{|c|}{ Preexisting eye disease } \\
\hline Post RD & 2 & & - & 1 \\
\hline DM & & 5 & 2 & 1 \\
\hline Glaucoma & & - & 1 & - \\
\hline $\begin{array}{l}\text { Myopic } \\
\text { degeneration }\end{array}$ & & 1 & 1 & - \\
\hline \multicolumn{5}{|l|}{ Nucleus size } \\
\hline $\begin{array}{l}\text { Whole } \\
\text { Nucleus }\end{array}$ & - & & 1 & 1 \\
\hline $\begin{array}{l}\text { More than } \\
\text { half }\end{array}$ & & 6 & 2 & - \\
\hline $\begin{array}{l}\text { Less than } \\
\text { half }\end{array}$ & & 4 & 3 & 2 \\
\hline \multicolumn{5}{|l|}{ Complication } \\
\hline $\begin{array}{l}\text { Choroidal } \\
\text { detachment }\end{array}$ & 2 & & 1 & \\
\hline High IOP & & & 1 & \\
\hline $\begin{array}{l}\text { Retinal } \\
\text { Detachment }\end{array}$ & 1 & & & 1 \\
\hline IOL drop & 1 & & & \\
\hline
\end{tabular}

\begin{tabular}{|c|c|c|c|c|c|c|}
\hline & Pre op & Post op & Pre op & Post op & Pre op & Post op \\
\hline \multicolumn{7}{|l|}{ BCVA } \\
\hline$\geq 0.5$ & 1 & 4 & 1 & 3 & & 1 \\
\hline$\geq 0.1-0.4$ & 1 & 4 & 1 & 1 & & 1 \\
\hline$\overline{<} 0.1$ & 8 & 2 & 4 & 2 & 3 & 1 \\
\hline \multicolumn{7}{|c|}{ Lens status } \\
\hline Aphakia & 7 & 3 & 5 & & 1 & \\
\hline PC IOL & 3 & 6 & 1 & 4 & 2 & 2 \\
\hline AC IOL & & 1 & & & & 1 \\
\hline Scleral & & & & 2 & & \\
\hline fixation & & & & & & \\
\hline
\end{tabular}

\section{Timing of Pars Plana Vitrectomy}

Ten patients (53\%) had vitrectomy within 1 day of phacoemulsification (Early Vitrectomy Group), 6 (32\%) within 1 week (Intermediate Vitrectomy Group), and 3 (15\%) after more than 1 week (Late Vitrectomy Group). The distributions of age, sex, clinical findings at presentation, visual acuity, lens status and dropped nucleus size are shown in table 3.

The visual acuity of Early Vitrectomy Group at presentation was worse than 0.1 in 8 of 10 patients. In 6 patients the dropped nucleus size was more than half, and less than half in 4 patients. At presentation 7 of 10 patient were aphakic, and the rest was pseudophakic with posterior chamber IOL in sulcus. Visual acuity improvement was noted in 8 of 10 patients (80\%). On the other hand, some complications were occurred in this group. Choroidal detachment was noted in 2 patients (20\%), IOL dropped followed by retinal detachment were 
noted in 1 patient (10\%). All of those 3 patients were left aphakic after vitrectomy due to severe choroidal detachment (2 patients). One patient with IOL dropped during vitrectomy was left aphakic after $\mathrm{IOL}$ extraction and retinal detachment surgery.

In Intermediate Vitrectomy Group, visual acuity at presentation was worse than 0.1 in 4 of 6 patients, and between 0.1 and 0.5 in 1 patient, and 1 patient had more than 0.5 . only 1 patient in this group had IOL implanted at presentation, 5 of 6 were aphakic. One patient had whole nucleus dropped. In 2 patients the dropped nucleus size was more than half and 3 patients has less than half nucleus dropped in vitreous cavity. One patient (16\%) had high intraocular pressure after vitrectomy and well controlled by anti-glaucoma medication, and 1 patients (16\%) had choroidal detachment after vitrectomy. Choroidal detachment was well resolved with steroid treatment. Scleral fixation IOL surgery was done in 2 patients in this group. Two of 6 (33\%) patient had visual acuity worse than $0.1,3$ patients (50\%) had more than 0.5 visual acuity and 1 patient (17\%) had visual acuity between 0.1 to 0.5 . Total 4 patients (67\%) had visual improvement after surgery.

In Late Vitrectomy group, all patient had visual acuity worse than 0.1 at presentation. One patient was aphakic and 2 patients were pseudophakic. Whole nucleus drop was noted in 1 case in this group while 2 patients had less than half nucleus dropped posteriorly. No patient in this group was aphakic, with 1 patient had anterior chamber IOL implanted. Only 1 complication recorded in this group. This complication was occurred in patient with history of retinal detachment. Visual acuity improvement were noted in 2 of 3 patient (67\%).

In general, 15 patients (79\%) had improvement visual acuity after vitrectomy. Fourteen of 19 patient (74\%) had final visual acuity better than 0.1 , with 6 patients (32\%) had final visual acuity between 0.1 and 0.5 and 8 patient (42\%) had visual acuity more than 0.5 . Complication were noted in 7 cases (34\%) and 4 of those complications were well managed with medication or surgery.

\section{DISCUSSION}

Indonesian reports on incidence and management of nucleus drop are limited. As phacoemulsification becomes the most popular technique for cataract surgery, there is an increase in the number of retained lens fragments after cataract surgery. Our incidence in nucleus drop was slightly lower than those identified with Mathai et al. ${ }^{2}$ They reported that nucleus drop incidence was $0.8 \%$ compare to our report $(0.14 \%)$. This result might be related to the phaco surgeon. In our study, all phaco surgeon are experience surgeon of Jakarta Eye Center while resident converting to phacoemulsification were included in Mathai et al report. ${ }^{2}$

Transconjunctival Sutureless Vitrectomy (TSV) methods was used in most cases in our hospital (89.5\%). This technique is allowed us to perform efficient vitrectomy under local anesthesia with minimally trauma, minimal astigmatism post vitrectomy and faster recovery compare to conventional technique. Furthermore, this technique can help surgeon to meet patient expectation. Unavailability of fragmatome in 23 Gauge and 25 gauges is the main limitation of this technique in nucleus drop cases. Both of 20 Gauge vitrectomy in our series were used in big nucleus size (whole nucleus and more than half nucleus) drop cases.

Most of our cases were implanted with PC-IOL. Scleral fixation IOL was noted in 2 cases (10\%), and AC-IOL was noted in 2 cases (10\%). This report is not too different to other series reported by Chen et all. ${ }^{11} \mathrm{Chen} C \mathrm{C}$ et al reported $13 \%$ AC-IOL and $14 \%$ scleral fixated IOL were implanted in their nucleus drop cases. This approach is dependent on multiple factors including the degree to which the capsular bag is intact and the type of intraocular lens that has been inserted. There are limited number of clinical trials comparing AC-IOL with scleral-fixated IOL, but the results show no significant superiority of one design over other, and therefore the choice of lens and method of fixation is still open to personal preference, availability and the individual surgeon's skill set. ${ }^{12}$

In our study, $40 \%$ in group early vitrectomy had vision 0.5 or better, $50 \%$ in group moderate vitrectomy had vision 0.5 or better, and $33 \%$ in group late vitrectomy had vision 0.5 or better. Over all we have $42 \%$ patients had visual acuity 0.5 or better. These results are not consistent with other study by Chen et $\mathrm{al}^{11}$. They found that immediate vitrectomy had better visual outcome than latter vitrectomy. In their study, $76 \%$ of the patients in group A (early vitrectomy) had a final visual acuity of $6 / 12$ or better; $45 \%$ of the patients in group B (within 1-week vitrectomy) had a final visual acuity of $6 / 12$ or better, and $28 \%$ of the patients in group C (late vitrectomy) had a final visual acuity of $6 / 12$ or better.

Complication was recorded in 7 cases (34\%). Complications that noted in our series were Retinal Detachment, IOL drop, Choroidal detachment, and high intra ocular pressure. In Chen et all ${ }^{11}$ study, no patient in same day vitrectomy or 1-week vitrectomy experienced retinal detachment, whereas in late vitrectomy group 55\% patient had retinal detachment after surgery. Kapusta et $\mathrm{al}^{13}$ reported no retinal detachment in their series, attributing this to the fact that cataract surgeon in their institution are discourage from attempting to retrieve nuclear fragments from deep within the vitreous cavity. On the other hand, in our study no patient in 1-week vitrectomy (intermediate vitrectomy) had retinal detachment while $10 \%$ patient in early vitrectomy (same day vitrectomy group) and 33\% patient in late vitrectomy group experienced retinal detachment after surgery. Those patients with retinal detachment has history of 
vitrectomy due to retinal detachment before cataract surgery. One patient in early vitrectomy group has experienced drop IOL in the end of vitrectomy. This condition was worsening to retinal detachment 1 week after vitrectomy. In this study early vitrectomy group has 3 patients (30\%) with complication, intermediate vitrectomy has $33 \%$ complication and, late vitrectomy has $33 \%$ complication.

In conclusion, the results of our study demonstrate that surgical management in cases of nucleus drop in JEC showed good result with very limited complications. In most cases vitrectomy was performed immediately after cataract surgery. Early vitrectomy has no significant differences in complications and visual outcome than 1week vitrectomy and late vitrectomy after cataract surgery. Further prospective study with higher number of cases may provide us with more insight into optimal result in nucleus drop management

\section{REFERENCES}

1. Pande $M$, Dabbs TR. Incidence of lens matter dislocating during phacoemulsification. J Cat Ref Surg 1996;22:737-42

2. Mathai A, Thomas R. Incidence and management of posteriorly dislocated nuclear fragments following phacoemulsification. Indian J Ophthalmol 1999;47:173

3. Kim JE, Flynn HW Jr, Smiddy WE, Murray TG, Rubsamen PE, Davis JL, Nicholson DH:Retained lens fragments after phacoemulsification.Ophthalmology 1994; 101: 1827-1832.

4. Vilar NF, Flynn HW Jr, Smiddy WE, MurrayTG, Davis JL, Rubsamen PE: Removal of retainedlens fragments after phacoemulsificationreverses secondary glaucoma and restoresvisual acuity. Ophthalmology 1997;104: 787-791.

5. Ross WH: Management of dislocated lens fragments after phacoemulsification surgery.Can J Ophthalmol 1996; 31: 234-240
6. Borne MJ, Tasman W, Regillo C, Malecha M,Sarin L: Outcomes of vitrectomy for retained lens fragments. Ophthalmology 1996; 103: 971-976.

7. Margherio RR, Margherio $A R$, PendergastSD, Williams GA, Garretson BR, Strong LE,Trese MT, Cox MS, Hassan TS: Vitrectomy for retained lens fragments after phacoemulsification. Ophthalmology 1997; 104: 1426-1432.

8. Al-Khaier A, Wong D, Lois N, Cota N, Yang YC, Groenewald C: Determinants of visual outcome after pars plana vitrectomy for posteriorly dislocated lens fragments in phacoemulsification. J Cataract Refract Surg 2001; 27: 1199-1206.

9. Hansson LJ, Larsson J: Vitrectomy for retained lens fragments in the vitreous after phacoemulsification. J Cataract Refract Surg 2002; 28: 1007-1011.

10. Rossetti A, Doro D: Retained intravitreal lens fragments after phacoemulsification:complications and visual outcome in vitrectomized and nonvitrectomized eyes. J Cataract Refract Surg 2002; 28: 310-315

11. Chen $\mathrm{CL}$, Wang TY, Cheng LH et al. Immediate Pars Plana Vitrectomy Improves Outcome in Retained Intravitreal Lens Fragments after Phacoemulsification.Ophthalmol 2008;222:27783

12. Bastawrous A, Parkes C, Prasad S. Choices in Correction of Aphakia during Vitrectomy.Ophthalmol 2011;226(suppl 1):46-52

13. Kapusta M,Chen JC, Lam WC. Outcomes of dropped nucleus during phacoemulsification.Ophthalmology 1996; 103: 1184-7

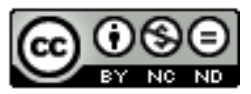

This work licensed under Creative Commons Attribution 